\title{
Challenges and Remedies in Interdisciplinary PG Programme
}

\author{
Ajitkumar. P. Madival ${ }^{1}$, M.B. Gorawar ${ }^{2}$, R.S. Hosmath ${ }^{3}$, P.P. Revankar ${ }^{4}$, R.P. Tapskar ${ }^{5}$, Ashok Kumbar \\ 1, 2, 3, 4, 5, 6 Departmentof Mechanical Engineering \\ B.V. Bhoomaraddi College of Engg. and Tech. \\ Hubballi, India-580031. \\ 1ajitkumarpm@gmail.com \\ ${ }^{2}$ mbgorwar@bvb.edu \\ ${ }^{3}$ rshosmath@bvb.edu \\ ${ }^{4}$ pp_revankar@bvb.edu \\ ${ }^{5}$ rptapaskar@bvb.edu \\ 6kumbarashokbe@gmail.com
}

\begin{abstract}
The world currently is reeling under acute shortage in essential resources for human existence due to growing population and elevated living standards. Today society at large demands more contributions from engineering community in terms of devising better and cost effective solutions to address existing problems. The engineering practice hence demands better skill sets that are honed to meet present day societal expectations. This situation demands improved teaching-learning methods that prepares engineering graduates to operate in multidisciplinary teams to accomplish the targeted solution or goal.

The present work showcases implementation of effective pedagogical approach in Computational fluid dynamics (CFD) laboratory course prescribed for interdisciplinary PG Programme in Energy Systems Engineering. The course intends to enable students in usage of computational tools that includes commercial and open source software packages for fluid flow analysis. The CFDcourse has application in diverse engineering domains as a precursor for selection and optimization of functional elements in products that involve fluid flows. The course delivery posed several challenges due to diversity within student group and need of mathematical proficiency. The exercises designed in CFD lab-course related to execution of complete cycle of analysis taking into account formulation and solution of fluid flow and heat transfer aspects. The course thereby related to attainment of Programme outcomes (POs) covering areas of Research capabilities, Competence on use of modern computational tools, Multi-disciplinary team activity and communication aspects.
\end{abstract}

Ajitkumar. P. Madival ${ }^{1}$

${ }^{1}$ Departmentof Mechanical Engineering

B.V. Bhoomaraddi College of Engg.and Tech.

Hubballi, India

1ªjitkumarpm@gmail.com
The results obtained provide useful inputs to develop measures that will improve the delivery of the course for next batch of students opting the course.

Keywords: CFD, Engineering Graduate Attributes

\section{Introduction}

CFD has emerged as a powerful tool for design and research studies involvingheat and mass transfer related problems. The CFD approach has made in-roads as an effective means for analysis in majority of the engineering disciplines. The wide application range of CFD has made it a multidisciplinary platform for the refinement of envisaged products related to electrical, electronics, construction, food processing, manufacturing and space technology. The CFD tools have been successfully deployed into different engineering problems like aerofoil design, optimization of air gap in generator, heat sink design for electronic gadgets and microwave heating.

The nature of current engineering problems has shifted to multi-physics arena that commands integration of different physical processes dependent on time and space as observed in micro electro mechanical systemsand combustion reaction in IC engines. This scenario of product design mandates for an engineer to have strong skillsetsin numerical modeling as evident from researchactivities in renewable energy. The industries today are heavily dependent on CFD tool for research and development activities that involve product optimizationbefore installation or launching the system.

There are some challenges in teaching CFD for the students which include strong mathematics skills and programming skills. CFD lab is a time intensive course with student performance evaluation based on the level of active involvement to analyze the independently defined task. The lab course helps students to connect to real world problemand obtain the solution through use of computational tool. Industries partners with educational 
institutes for CFD related research that leads to some breakthrough solutions to industry problems.

\section{Literature review}

The experiences of different educational institutes gravitate on the need to enhance quality of education at all three levels that includes student, teacher and educational institution. The frame work promotes on time solutions to existing societal problems and adds value all three levels of pedagogy cycle. The modified approach addresses educational reforms that demands adoption of newer and better learning models to promote innovation in education. To develop pedagogical set up for the new teaching technique to achieve learning in all three layers of education. To ensure quality education the soundness between the layers and constructive alignment in the layer was aprerequisite.The proposed model for effective learning integrated information, motivation, activity, interaction and production. [1]

The better pedagogy for teaching CFD course was to develop core mathematics through step-by-step procedure with no assumptions to neglect any terms. CFD course should foster clear understandingof conservation laws and mathematical equations thatare helpful for effective use of CFD [2]. The importance of selecting simple real time problem for the introduction of CFD lab with comparison of solutions obtained by coding problem and commercialCFD package was emphasized to motivatestudents that promoted attainment of learning outcomes [3].

The use of CFD software tools ensured better quality of analysis due to lower time consumption as compared to lecture mode of delivery on the topic. This reduces startup time as well as valuable lecture time. CFD software tools provide structured learning experience, ensuring proper pedagogy to assimilatetheoretical concepts linked to the solution. Simultaneous analytical theory and experimental correlation to engineering problems can be visualized with the help of CFD software tool [4]. The CFD results through simulation study allowed student to visualize flow based on contour plots that significantly enhanced learning. The tool provided provision for changes in the geometry and fluidproperties facilitating students to explore the effects of these variables [5].

The simultaneous learning of theory and laboratory courses helped in improvement of teaching modules and facilitatedstudents to understand coursein greater depth [6]. The present education system has to be aligned towards integration of different disciplines into transcend disciplinary specialization by inter, multi and transdisciplinary approaches. The Industry view dictates necessity to have practical knowledge rather than restricting to only theoretical knowhow [7]. The pedagogy research proposed restructuring of education system to enhance effectiveness of education that included the shift from,

- Whole class to small group.
- Lecture to coaching mode for more engaged students.

- Work with better students to work with all students.

- Assessment based on test performance to assessment based on products, progress and effort.

- Competitive to cooperative social structure.

- All learners learning same things to different students learning different things.

- Verbal thinking to the integration of the visual and verbal thinking.[8]

\section{Details of Course for pedagogy reforms}

The Energy systems Engineering PG program spans two year durationoffered to students holding UG degree in various streams of Engineering including streams of Mechanicaland Electrical.

The program is designed such as to stress more on teaching how to learn rather than just teaching the subjects which is realized by self-study component. The different courses taught in the program are Computational fluid dynamics, Conventional energy conversion systems, Renewable energy conversion systems (mainly focusing on Wind and Solar energy systems), Systems modelling and analysis and Sustainable building design. Each subject facilitates student to work on course project which involves application of theory knowledge of the subject in to live examples. After completion of three semesters each student has to individually handle the individual research project which takes lion share in the credits allotted for the program. In which the student has to implement the theoretical knowledge gained in the program to create innovative product. In doing so CFD tool skills helped students to create and understand the behavior of the product computationally saving time. In order to improve the skills in dealing with CFD tool this lab course was introduced as part of the PG Programme.

The lab course was designed for beginners with limited knowledge of 3D modelling software packages and hence the course commenced with introduction to the geometry, Grid generation, Specifications of boundary conditions, Different methods used for the simulation and analysis ofsimulation results. Each session included relevant introduction on the topic and governing equations were discussed.Thisapproach helped clear visualization of CFD tool instead of treating it as a black box. The hands-on experience on CFD was ensured to students in this lab sessions through extensive activity based learning through simulation tools.

\section{Methodology of Course Delivery}

The course was delivered based on the Lebrun's learning model that emphasized on integration of Information, Motivation, Activities, interaction and production. In the beginning of the course the learning outcomes are set which in turn made the course goal oriented. The details of the outcome based jargon connected to CFD course is briefed in this section.

Course learning outcomes:

By the end of the course student should be able to

- Model the 3D geometry for given problem.

- Select appropriate dimensions for flow domain. 
- Select proper mesh.

- Define initial and boundary conditions.

- Test convergence of solution.

- Interpret post processing results.

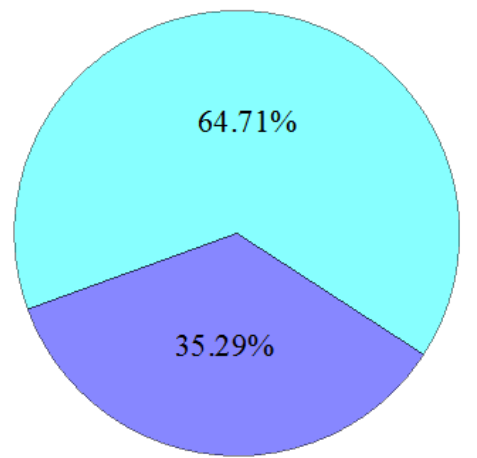

\section{Mechanical Science $\square$ Electrical Science}

Fig.1. Details of Students background

Majority of the students $(64.71 \%)$ were from electrical science background not familiar with the modelling tools. In order to provide bridging knowledge on basics of modeling to students from electrical background and simultaneously keeping Mechanical science students in the flow in the same time a shift from whole class to small group is realized. Group of 3 members was created such that each group containedone member from mechanical background and 2 students from electrical science background.

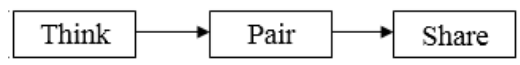

Fig. 2. Conceptual approach for course delivery

To enhance the learning ability coaching methodology adopted rather than giving lecture on the course.

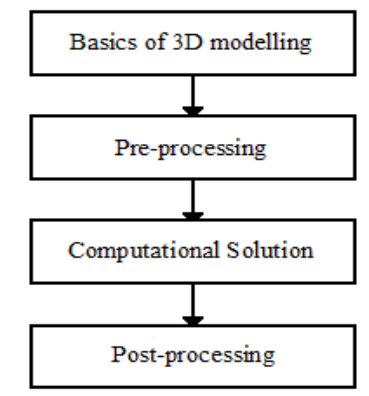

Fig.3. Methodology of CFD course delivery

\section{Results and Discussions:}

The results obtained from the performance assessment of the student and student feedback for the course are put in graphical form and discussed in this section.

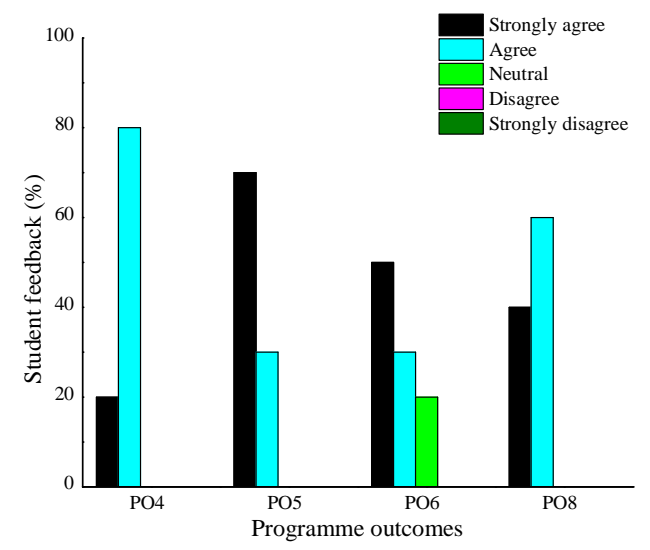

Fig. 4. Details of Qualitative attainment of Programme outcome

The student perception on the course delivery was assessed based on course feedback obtained on completion of lab course as highlighted in annexure 2 . The course content and attainment in specific course objectives were assessed through questionnaire with respective results pointed out through figures 4 and 5 . The qualitative attainment of POs indicated $20 \%, 70 \%$, $50 \%$ and $40 \%$ strongly in agreement with PO4, PO5, PO6 and PO8 respectively. This was attributed to effective delivery of the computational tool usage and promotion of effective multidisciplinary team formation. Similarly a marginally reduced satisfaction in the PO6 outcome with $20 \%$ respondents giving a neutral response. However the overall picture of attainment based on a quantitative yardstick is encouraging with three out of four attributes scoring within the top two bands. The fig. 5 reveals that there has been a net positive value addition with respect to all the six functional entities of CFD tool usage with marginal differences between each other entity. The results were not evaluated based upon stream-wise categorization owing to anonymous feedback being collected from the respondents. Thus students have benefitted from the modified pedagogical approach in delivery of the lab course.

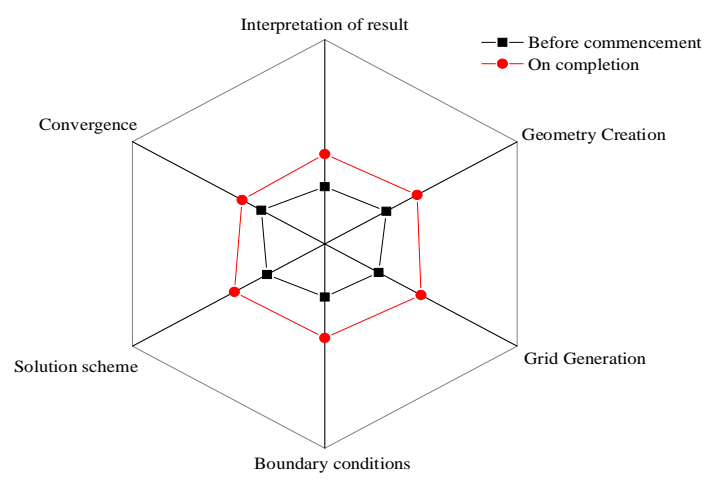

Fig. 5. Assessment with respect to value addition to students 


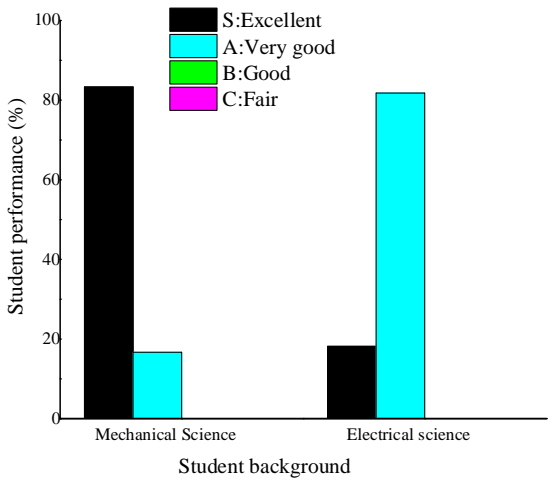

Fig. 6. Quantitative details of student performance

Fig. 6 shows that student performance in the lab course to be $83 \%$ and $18 \%$ under $\mathrm{S}$ grade respectively for mechanical and electrical background respectively. This is attributed to co-learning amongst the two streams and directed efforts in course delivery through conscious group formation based upon Lebrun's learning model. The overall success rate of the course based on the assessment indicated $100 \%$ with students from both streams aggregating in the top two grades(S and $\mathrm{A})$, however the students of mechanical stream performed better than their electrical counterparts owing to a higher level of familiarization with the concepts dealt in the course. However individual attribute-wise performance contributing to overall course performance is not reported in this work due to non-availability of data. The current assessment strategy adopted for the present batch of students will overcome this drawback by individual attribute-wise performance tracking.

\section{Conclusions}

The following conclusions were drawn through the qualitative and quantitative analysis of the present study,

- The Lebrun Learning model of think-pair-share was effective to disseminate knowledge of interdisciplinary nature to learning group with diverse background.

- The students are more receptive to learning through peer groups that are meticulously formed to generate a culture of interdependence.

- The effectiveness of the approach adopted for the lab course was evident through the results of attainment in $\mathrm{PO} 4, \mathrm{PO} 5, \mathrm{PO} 6$ and $\mathrm{PO} 8$ that respectively were rated at $20 \%, 70 \%, 50 \%$ and $40 \%$ strong agreement.

- The qualitative assessment indicated that $20 \%$ of the respondents were not in the delight zone in terms of effectiveness of team-work attribute addressed through the proposed approach. This deviation was attributed to individual personality traits within the learners that prohibits team formation and working in groups.

- The course delivery resulted in a net positive value addition in the selected domain area in CFD but however with standard deviations of scores in CFD lab course within Electrical stream and Mechanical stream to be respectively 4.45 and 3.90 while the overall

\section{JeË}

standard deviation was 5.36 for both streams put together.

- In absolute grading terminology student performance in the lab course was $83 \%$ and $18 \%$ under S grade respectively for mechanical and electrical streams indicating that interdisciplinary courses strongly aligned to a particular stream poses challenges in terms of receptivity by the alien stream in the group.

- The pedagogical approach for interdisciplinary program should be designed to align the interests of participating groups and build a synergic fusion to tackle real world problems that are largely inter-disciplinary in content and execution.

- The present ordeal needs implementation of certain modifications that can incorporate other approaches like Kolb experiential and BYO-IDEAHO learning models.

\section{Acknowledgements}

The authors express their heartfelt gratitude to the Management KLE Society Belagavi, honorable ViceChancellor, KLE Tech. University Hubballi, TEQIP funding agency and all other individuals and Departments for their support provided during the implementation of new pedagogical approach.

\section{References}

1. Marcel Lebrun, Quality Towards an Expected Harmony: Pedagogy and Technology Speaking Together About Innovation, AACE Journal, 15(2) 2007, 115-130.

2. Jiyuan $\mathrm{Tu}$, Guan-Heng Yeoh, Chaoqun Liu, Computational Fluid Dynamics: A Practical Approach, Elsevier publications, Second edition, 2013.

3. Willy Morscheidt, Simeon Cavadias, Frederic Rousseau, Bradley Da Silva, Pollution of the Rhine River: An Introduction to Numerical Modelling, Education for Chemical Engineers, 8, 2013, 119-123.

4. Curtis. J.S, Henthom. K, Moeykens. S, Krishnan. M., Enhancing the Teaching of Fluid Mechanics and Transport Phenomena via Flow Lab- a Computational Fluid Dynamics Tool, Proceedings of ASME Heat transfer/ Fluid Engineering Summer Conference, 2004, 165-174.

5. Madeira, L.M., Alves, M.A., Rodrigues, A.E. Teaching Non Ideal Reactors with CFD Tools, Chemical Engineering Education, Volume 38, 2004, $154-160$.

6. Stern, F., Xing, T., Muste, M., Yarbrough, D., Rothmayer, A., Rajagopalan, G., Caughey, D., Bhaskaran, R., Smith, S., Hutchings, B. Integration of Simulation Technology into Undergraduate Engineering Courses and Laboratories, ASEE Annual Conference Proceedings, 2003, pp 28072818.

7. Jennifer M. Gidley, Evolution of Education: From Weak Signals to Rich Imaginaries of educational futures, Futures 44, 2012, 46-54. 
Journal of Engineering Education Transformations, Special Issue, elSSN 2394-1707

8. Bagley, C., \& Hunter, B. (1992). Restructuring, constructivism, and technology: Forging a new relationship. Educational Technology, 7, 22-27. 


\section{ANNEXURE 1}

Table A1. Assessment criteria used to analyze the effectiveness of the course

\begin{tabular}{|l|l|c|}
\hline & \multicolumn{1}{|c|}{ Assessment Criteria } & Weightage \\
\hline PO-4 & $\begin{array}{l}\text { Ability to carry out research by identifying the problem, synthesis through literature survey, } \\
\text { designing and conducting the experiments, analyzing and interpreting the results related to energy } \\
\text { systems engineering. }\end{array}$ & $40 \%$ \\
\hline PO-5 & $\begin{array}{l}\text { Ability to use modern computational tools in modeling, simulation and analysis of energy systems } \\
\text { engineering related problems. }\end{array}$ & $40 \%$ \\
\hline PO-6 & $\begin{array}{l}\text { Ability to participate effectively in multidisciplinary teams and contribute towards achieving } \\
\text { common goals of the team. }\end{array}$ & $10 \%$ \\
\hline PO-8 & $\begin{array}{l}\text { Ability to communicate effectively in both oral and written forms with superiors, subordinates, peers } \\
\text { and other stake holders. }\end{array}$ & $10 \%$ \\
\hline
\end{tabular}

ANNEXURE 2

\section{Feedback form for Qualitative assessment of CFD Lab course Course title and code: CFD Lab MESL505 \\ I Course content and delivery}

Indicate your perception on the given parameters based on your experience from the stated course

Rate on 1 to 5 scale: 1: strong disagreement ........5: Strong agreement

\begin{tabular}{|c|l|c|}
\hline Sl.No & \multicolumn{1}{|c|}{ Parameters } & Rating (1-5 scale) \\
\hline 1 & Contents of the lab & \\
\hline 2 & Modeling of the given problem & \\
\hline 3 & Improvement in competence to handle the tool individually & \\
\hline 4 & Work in multidisciplinary teams & \\
\hline 5 & Effectiveness to communicate in oral and written mode & \\
\hline 6 & Quality of delivery of course content & \\
\hline 7 & Competence to analyze real world fluid flow problem & \\
\hline
\end{tabular}

\section{Value addition through CFD Lab course}

Indicate your perception on the given parameters with respect to value addition through the CFD Lab course

Rate on 1 to 5 scale: 1: Strong disagreement ........5: Strong agreement

\begin{tabular}{|c|l|l|l|}
\hline Sl.No & \multicolumn{1}{|c|}{ Parameters } & Before CFD lab & On completion of CFD lab \\
\hline 1 & Geometry creation & & \\
\hline 2 & Grid generation & \\
\hline 3 & Specifying Boundary conditions & & \\
\hline 4 & Solving of CFD problem & & \\
\hline 5 & Convergence of result & & \\
\hline 6 & Interpretation of CFD results & & \\
\hline
\end{tabular}

